\title{
Capnography improves detection of apnea during procedural sedation for percutaneous transhepatic cholangiodrainage
}

\author{
Christoph Schlag MD¹, Alexandra Wörner MD¹, Stefan Wagenpfeil PhD², Eberhard F Kochs $\mathrm{MD}^{3}$, \\ Roland M Schmid MD ${ }^{1}$, Stefan von Delius MD $^{1}$
}

C Schlag, A Wörner, S Wagenpfeil, EF Kochs, RM Schmid, $\mathrm{S}$ von Delius. Capnography improves detection of apnea during procedural sedation for percutaneous transhepatic cholangiodrainage. Can J Gastroenterol 2013;27(10):582-586.

BACKGROUND: Capnography provides noninvasive monitoring of ventilation and can enable early recognition of altered respiration patterns and apnea.

OBJECTIVE: To compare the detection of apnea and the prediction of oxygen desaturation and hypoxemia using capnography versus clinical surveillance during procedural sedation for percutaneous transhepatic cholangiodrainage (PTCD).

METHODS: Twenty consecutive patients scheduled for PTCD were included in the study. All patients were sedated during the procedure using midazolam and propofol. Aside from standard monitoring, additional capnographic monitoring was used and analyzed by an independent observer.

RESULTS: The mean ( \pm SD) cumulative duration of apnea demonstrated by capnography was significantly longer than the mean cumulative duration of clinically detected apnea $(207.5 \pm 348.8 \mathrm{~s}$ versus $8.2 \pm 17.9 \mathrm{~s} ; \mathrm{P}=0.015)$. The overall number of detected episodes of apnea was also significantly different (113 versus seven; $\mathrm{P}=0.012$ ). There were 15 events of oxygen desaturation (decrease in oxygen saturation $\left[\mathrm{SaO}_{2}\right] \geq 5 \%$ ), which were predicted in eight of 15 cases by capnography and in one of 15 cases by clinical observation. There were three events of hypoxemia $\left(\mathrm{SaO}_{2}<90 \%\right)$ that were predicted in three of three cases by capnography and in one of three cases by clinical observation.

CONCLUSION: Capnographic monitoring was superior to clinical surveillance in the detection of apnea and in the prediction of oxygen desaturation during procedural sedation for PTCD.

\author{
La capnographie permet de mieux déceler l'apnée \\ pendant une sédation en vue d'un \\ cholangiodrainage transhépatique percutané
}

HISTORIQUE : La capnographie assure une surveillance non invasive de la ventilation et peut permettre de déceler rapidement les altérations des profils respiratoires, de même que l'apnée.

OBJECTIF : Comparer la détection de l'apnée et la prédiction de la désaturation en oxygène et de l'hypoxémie à l'aide de la capnographie, d'une part, à la surveillance clinique pendant une sédation en vue d'un cholangiodrainage transhépatique percutané (CDTP), d'autre part. MÉTHODOLOGIE : Vingt patients consécutifs qui devaient subir un CDTP ont participé à l'étude. Tous les patients étaient sous sédation pendant l'intervention, au moyen de midazolam et de propofol. En plus de la surveillance habituelle, les chercheurs ont recouru à la surveillance par capnographie, qui a été analysée par un observateur indépendant. RÉSULTATS : La durée cumulative moyenne $( \pm E ́ T)$ de l'apnée démontrée par capnographie était considérablement plus longue que celle décelée cliniquement $(207,5 \pm 348,8 \mathrm{~s}$ par rapport à $8,2 \pm 17,9 \mathrm{~s}$; $\mathrm{P}=0,015)$. Le nombre global d'épisodes d'apnée décelés différait également de manière significative (113 par rapport à sept; $\mathrm{P}=0,012)$. Les chercheurs ont recensé 15 cas de désaturation en oxygène (diminution de la saturation en oxygène $\left[\mathrm{SaO}_{2}\right] \geq 5 \%$ ), que la capnographie a prédit dans huit des 15 cas, tandis que l'observation clinique ne l'a prédite que dans un des 15 cas. La capnographie a permis de prédire les trois cas d'hypoxémie $\left(\mathrm{SaO}_{2}<90 \%\right)$, tandis que l'observation clinique n'en a prédit qu'un seul.

CONCLUSION : La surveillance par capnographie est supérieure à la surveillance clinique pour déceler l'apnée et prédire la désaturation en oxygène pendant une sédation en vue d'un CDTP.

Key Words: Capnography; Hypoxemia; PTCD; Sedation

Dercutaneous transhepatic cholangiodrainage (PTCD) is an alterna1 tive method for drainage of bile when endoscopic retrograde cholangiography is not feasible (eg, in patients with pyloric stenosis or altered anatomy of the upper gastrointestinal tract) (1). For PTCD, the bile duct must be percutanously punctured, which can cause severe pain and vasovagal reactions. Therefore, the use of sedative and/or analgesic drugs is usually necessary before and during the procedure. Judicious management of procedural sedation is critical. Oversedation may lead to airway obstruction, aspiration, respiratory depression and hemodynamic instability. In contrast, undersedation can cause considerable discomfort for the patient. Standard monitoring of the patient includes pulse oximetry as well as blood pressure measurements and electrocardiographic monitoring in selected patients. In the absence of hypoxemia, ventilation is primarily driven by arterial carbon dioxide $\left(\mathrm{CO}_{2}\right)$ tension; significant alveolar hypoventilation and apnea may occur in the presence of normal oxygen saturation $\left(\mathrm{SaO}_{2}\right)$

\begin{abstract}
demonstrated by pulse oximetry. Therefore, guidelines recommend continuous monitoring of respiratory function and pulmonary ventilation in patients undergoing conscious sedation (2-4). It has been shown that capnography is superior to clinical monitoring for detecting respiratory abnormalities during procedural sedation (5). Capnography offers a quantitative numerical reading and graphic waveform that measures, illustrates and documents a patient's exhaled $\mathrm{CO}_{2}$ levels (6). It provides a real-time graphic assessment of ventilation and can act as an early warning system for impending respiratory compromise and resultant hypoxemia.

To date, the use of capnography during procedural sedation for PTCD has not been evaluated. Therefore, the aim of the present prospective study was to compare the detection rates of apnea using capnography versus clinical surveillance during sedation for PTCD. In addition, correlations among apnea, oxygen desaturation and hypoxemia were evaluated in detail.
\end{abstract}

${ }^{1}$ II. Medizinische Klinik und Poliklinik; ${ }^{2}$ Institut für Medizinische Statistik und Epidemiologie; ${ }^{3}$ Klinik für Anästhesiologie, Klinikum rechts der Isar, Technische Universität München, Munich, Germany

Correspondence: Dr Christoph Schlag, Klinikum rechts der Isar der Technischen Universität München, II. Medizinische Klinik, Ismaninger Str. 22,

81675 Munich, Germany. Telephone 49-89-41402454, fax 49-89-41404905, e-mail christoph.schlag@lrz.tum.de

Received for publication September 15, 2012. Accepted June 16, 2013 


\section{METHODS}

Study population

The study protocol was approved by the local ethics committee and registered at ClinicalTrials.gov (Identifier: NCT01587157). Consecutive patients were enrolled between August 2010 and June 2011. Patients undergoing PTCD under sedation were considered for inclusion. Exclusion criteria were: age $<18$ years, American Society of Anesthesiologists (ASA) class V, allergy to narcotic drugs, pregnancy, pre-existing hypotension (systolic blood pressure $<90 \mathrm{mmHg}$ ), bradycardia (heart rate $<50$ beats $/ \mathrm{min}$ ) or hypoxemia $\left(\mathrm{SaO}_{2}<90 \%\right)$. Written informed consent was obtained from all patients.

\section{Study design}

The study was a prospective single-centre trial performed in the endoscopy unit of the II. Medizinische Klinik, Klinikum rechts der Isar, Technische Universität München, Munich, Germany.

\section{Patient demographics and procedure variables}

Several patient variables were obtained including age, sex, body mass index, history of smoking, history of alcohol abuse, regular use of benzodiazepines or narcotic medications, sleep apnea, ASA status, Mallampati score and problems during previous procedural sedation. Procedural variables included whether the patients were outpatients or inpatients, baseline $\mathrm{SaO}_{2}$ after oxygen supplementation at $2 \mathrm{~L} / \mathrm{min}$, heart rate and systolic blood pressure, indications for PTCD, doses of medications during the procedure and duration of the PTCD procedure.

\section{Study procedure}

The PTCD procedures were performed with the patients supine by experienced gastroenterologists. A second physician, who was experienced in intensive care medicine and resuscitation (which included formal training in bag-valve-mask ventilation and different intubation procedures), was responsible for the administration of the sedative drugs, continuous monitoring of vital parameters and the clinical assessment of respiratory activity.

Initial and subsequent administration of sedative drugs was applied to achieve and maintain an adequate level of sedation. All patients received an intravenous loading dose of $2.5 \mathrm{mg}$ midazolam (Ratiopharm, Germany) and $1 \%$ propofol (Fresenius Kabi, Germany) adjusted to bodyweight ( $40 \mathrm{mg}$ at $<70 \mathrm{~kg}$ bodyweight or $60 \mathrm{mg}$ at $\geq 70 \mathrm{~kg}$ body weight) and, if necessary, to age and comorbidity of the patient (patients of advanced age or with pre-existing neurological disease received only an initial propofol dose of $20 \mathrm{mg}$ ). After the loading dose was injected, repeated doses of $10 \mathrm{mg}$ to $20 \mathrm{mg}$ of propofol were given intravenously (with no limit on total dose). All vital signs, including blood pressure, oxygen saturation and heart rate, were checked before administering any sedative medication.

Monitoring: During the procedure, the patients were monitored for clinical signs of respiratory abnormalities. Heart rate, pulse oximetry and electrocardiographic changes were continuously assessed. Noninvasive blood pressure was automatically assessed at $3 \mathrm{~min}$ intervals. Abnormal events detected on heart rate, pulse oximetry and blood pressure measurements were crosschecked for any mechanical issues related to devices and sensors. In addition, capnographic monitoring (Capnostream 20, Covidien, USA), which was neither visible to the physician performing the procedure nor to the physician administering the sedation, was applied and analyzed by a third independent observer who was not involved in the procedure. The display of the capnography monitor was simply turned away and all acoustic alarms were turned off. For capnography, a nasal cannula with an oral sampling port to accommodate mouth breathers provided $2 \mathrm{~L} / \mathrm{min}$ of oxygen and continuously sampled $\mathrm{CO}_{2}$ content of both inspired and expired gas (Smart CapnoLine Plus, Covidien, USA). The sampling line was connected to a portable bedside monitor (Capnostream 20, Covidien, USA) that displayed the time-based $\mathrm{CO}_{2}$ graphic waveform, the numerical $\mathrm{CO}_{2}$ partial pressure $(\mathrm{mmHg})$, the derived respiratory rate and the $\mathrm{SaO}_{2}$ by integrated pulse oximetry (Nellcor,
Covidien, USA). The capnogram's height, shape and rhythm provide a real-time assessment of ventilatory function. During inspiration, gas samples essentially contain no $\mathrm{CO}_{2}$ in the presence of supplemental oxygen and, during expiration, samples approximately represent alveolar $\mathrm{CO}_{2}$ concentration with a small amount of gas containing nearly no $\mathrm{CO}_{2}$ from patient's physiological dead space. In the case of alveolar hypoventilation, samples contain reduced to no $\mathrm{CO}_{2}$. All patients had a run-in of several minutes before the first dose of medication was given, which signalled the beginning of sedation. The third independent observer documented the frequency and duration of clinically detected episodes of apnea that were observed and communicated by the physician providing sedation, as well as the frequency and duration of the episodes of apnea, as detected by capnographic monitoring, on a standardized case report form. Frequency and duration of complications (oxygen desaturation [decreases in $\mathrm{SaO}_{2} \geq 5 \%$ compared with baseline) and hypoxemia $\left(\mathrm{SaO}_{2}<90 \%\right)$, hypotension (systolic blood pressure $<90 \mathrm{mmHg}$ ) and bradycardia (heart rate $<50$ beats/min) were also documented.

Apnea was clinically defined when cessation of breathing was observed by the physician who was responsible for sedation. Capnographically detected apnea was defined as a decrease of exhaled partial pressure of $\mathrm{CO}_{2}<8 \mathrm{mmHg}$ for $\geq 15 \mathrm{~s}$ according to previously published studies $(7,8)$. Clinically detected apnea, oxygen desaturation and hypoxemia prompted an intervention that consisted of patient stimulation, withholding medication, a chin lift or jaw thrust manoeuvre, or increasing oxygen supplementation.

Following completion of PTCD, patients were disconnected from electronic monitoring after they could give a meaningful verbal response and vital parameters were stable. The patients were then transferred to the recovery area. After full recovery, patients were asked to rate their satisfaction with the sedation on a numerical analogue scale (1 [minimum] to 10 [maximum]) and were then discharged from the endoscopy unit. Patients' cooperation during endoscopy was rated by the examiner, who was not involved in the administration of medication, on a numerical analogue scale (1 [minimum] to 10 [maximum]) on completion of the procedure.

\section{Study outcome}

The primary study end point was the mean cumulative duration of detected apnea (capnographic versus clinical surveillance) during procedural sedation for PTCD. The time span of sedation was defined from the start of the first administration of medication until the disconnection of electronic monitoring after completion of the procedure.

Secondary end points included the overall number of detected episodes of apnea (capnographic versus clinical surveillance), the occurrence of oxygen desaturation (decrease in $\mathrm{SaO}_{2} \geq 5 \%$ ) and hypoxemia $\left(\mathrm{SaO}_{2}<90 \%\right)$, bradycardia (heart rate $<50$ beats $/ \mathrm{min}$ ), hypotension (systolic blood pressure $<90 \mathrm{mmHg}$ ), requirement of increased oxygen supplementation ( $>2 \mathrm{~L} / \mathrm{min}$ ), assisted ventilation, overall number of complications, examiner's and patient's satisfaction with the sedation, and time of patients' recovery after sedation.

\section{Sample size estimations}

Sample size calculations were performed using nQuery Advisor version 7.0 (Statistical Solutions, Ireland). A sample size of 20 patients had $80 \%$ power to detect a difference in the mean duration of detected apnea of $100 \mathrm{~s}$ (ie, a mean cumulative duration for clinical surveillance of $100 \mathrm{~s}$ and for capnographic surveillance of $200 \mathrm{~s}$, respectively), assuming an SD of differences of $150 \mathrm{~s}$ and using a paired $t$ test with a 0.05 two-sided significance level.

\section{Statistical analysis}

Descriptive statistics were computed for all variables to provide means and SDs for continuous variables and frequencies for categorical variables. P values correspond to paired $t$ tests ( $t$ test for two dependent samples) for quantitative and exact McNemar tests (unconditional) for binary data, respectively, and are subject to a local two-sided 
TABLE 1

Demographic, clinical and procedural characteristics of the subjects

\begin{tabular}{|c|c|}
\hline Factor & $(n=20)$ \\
\hline Age, years, mean \pm SD & $62.5 \pm 11.3$ \\
\hline Male sex & $12(60.0)$ \\
\hline Body mass index, $\mathrm{kg} / \mathrm{m}^{2}$, mean $\pm \mathrm{SD}$ & $21.9 \pm 3.5$ \\
\hline Smoking (current and ex) & $8(40.0)$ \\
\hline Alcohol abuse (current and ex) & $4(20.0)$ \\
\hline Regular narcotic/sedative use & $1(5.0)$ \\
\hline Sleep apnea & $0(0)$ \\
\hline \multicolumn{2}{|l|}{ Mallampati score } \\
\hline 1 & $4(20.0)$ \\
\hline 2 & $9(45.0)$ \\
\hline 3 & $1(5.0)$ \\
\hline 4 & $6(30)$ \\
\hline \multicolumn{2}{|l|}{ ASA class } \\
\hline 1 & $0(0)$ \\
\hline 2 & $7(35.0)$ \\
\hline 3 & $12(60.0)$ \\
\hline 4 & $1(5.0)$ \\
\hline Sedation problems during previous endoscopies & $0(0)$ \\
\hline Inpatients & $19(95.0)$ \\
\hline Outpatients & $1(5.0)$ \\
\hline \multicolumn{2}{|l|}{ Indications } \\
\hline Benign biliary stenosis & $6(30.0)$ \\
\hline Biliodigestive anastomosis & $4(20.0)$ \\
\hline Chronic pancreatitis & $2(10.0)$ \\
\hline Malignant biliary stenosis & $14(70.0)$ \\
\hline Cholangiocellular carcinoma & $5(25.0)$ \\
\hline Pancreatic cancer & $5(25.0)$ \\
\hline Gastric cancer & $3(15.0)$ \\
\hline Hepatocellular carcinoma & $1(5.0)$ \\
\hline New PTCD & $8(40.0)$ \\
\hline PTCD exchange & $6(30.0)$ \\
\hline PTCD dilation & $6(30.0)$ \\
\hline Baseline oxygen saturation, $\%$, mean \pm SD & $99.4 \pm 0.8$ \\
\hline Baseline heart rate, beats/min, mean \pm SD & $82.6 \pm 15.6$ \\
\hline Baseline systolic blood pressure, $\mathrm{mmHg}$, mean $\pm \mathrm{SD}$ & $141.4 \pm 23.9$ \\
\hline Procedural time, min, mean \pm SD & $32.9 \pm 21.2$ \\
\hline Total midazolam dose, $\mathrm{mg}$, mean $\pm \mathrm{SD}$ & $2.5 \pm 0$ \\
\hline Total propofol dose, mg, mean \pm SD & $274.3 \pm 222.8$ \\
\hline
\end{tabular}

Data presented as $n$ (\%) unless otherwise indicated. ASA American Association of Anesthesiologists; PTCD Percutaneous transhepatic cholangiodrainage

significance level of 5\%. Predictive Analytics SoftWare version 18.0 (IBM Corporation, USA) for Windows (Microsoft Corporation, USA) and StatXact version 5.0.3 (Cytel Software Corporation, USA) were used to perform all statistical analyses and Microsoft Excel 2007 (Microsoft Corporation, USA) for data handling.

\section{RESULTS}

Demographic, clinical and procedural characteristics of subjects are summarized in Table 1 . Twenty patients ( 12 men, eight women; mean [ $\pm \mathrm{SD}$ ] age $62.5 \pm 11.3$ years,) participated in the study; 19 were inpatients, seven patients were ASA class II, 12 patients were ASA class III and one patient was ASA class IV; four patients had a Mallampati score of 1 , nine patients had a score of 2 , one patient had a score of 3 and six patients had a score of 4 . No patient had sleep apnea. Mean body mass index was $21.9 \pm 3.5 \mathrm{~kg} / \mathrm{m}^{2}$. Present or former tobacco and ethanol abuse were reported by eight and four patients, respectively. No patient experienced problems during previous sedations. One patient used benzodiazepines or narcotic drugs regularly.
TABLE 2

Study outcomes

\begin{tabular}{|c|c|c|}
\hline \multicolumn{3}{|l|}{ Primary end points } \\
\hline $\begin{array}{l}\text { Cumulative duration of apnea detected by } \\
\text { capnography, s, mean } \pm \mathrm{SD}\end{array}$ & $207.5 \pm 348.8$ & $P=0.015^{\star}$ \\
\hline $\begin{array}{l}\text { Cumulative duration of apnea detected } \\
\text { clinically, } S \text {, mean } \pm S D\end{array}$ & $8.2 \pm 17.9$ & \\
\hline \multicolumn{3}{|l|}{ Secondary end points (number of patients) } \\
\hline $\begin{array}{l}\text { Episodes of apnea detected by capnography } \\
(\mathrm{n}=16)\end{array}$ & 113 & $\mathrm{P}=0.001^{\dagger}$ \\
\hline Episodes of apnea detected clinically $(n=6)$ & 7 & \\
\hline Episodes of oxygen desaturation $(n=10)$ & 15 & $P=0.06^{\dagger}$ \\
\hline Predicted by capnography $(n=8)$ & 8 & \\
\hline Predicted clinically $(n=2)$ & 2 & \\
\hline Episodes of hypoxemia $(n=3)$ & 3 & $\mathrm{P}=0.22^{\dagger}$ \\
\hline Predicted by capnography $(n=3)$ & 3 & \\
\hline Predicted clinically $(n=1)$ & 1 & \\
\hline Episodes of bradycardia $(n=0)$ & 0 & \\
\hline Episodes of hypotension $(n=2)$ & 2 & \\
\hline Increased oxygen supplementation $(n=3)$ & 3 & \\
\hline Serious adverse advents $(n=0)$ & 0 & \\
\hline $\begin{array}{l}\text { Patient cooperation rated by examiner } \\
\text { (NAS, 1-10), mean } \pm S D\end{array}$ & $8.5 \pm 1.3$ & \\
\hline Patient satisfaction (NAS, 1-10), mean \pm SD & $9.1 \pm 1.6$ & \\
\hline $\begin{array}{l}\text { Time from end of procedure until eye opening, } \\
\text { min, mean } \pm \text { SD }\end{array}$ & $4.8 \pm 3.3$ & \\
\hline
\end{tabular}

Data presented as $n$ unless otherwise indicated. *Paired $\mathrm{t}$ test; ${ }^{\dagger}$ Exact, unconditional McNemar test. NAS Numerical analogue scale

Mean baseline $\mathrm{SaO}_{2}$ was $99.4 \pm 0.8 \%$, baseline heart rate was $82.6 \pm 15.6$ beats $/ \mathrm{min}$ and baseline systolic blood pressure was $141.4 \pm 23.9 \mathrm{mmHg}$. All PTCDs $(\mathrm{n}=20)$ were performed under sedation with midazolam $(2.5 \pm 0 \mathrm{mg})$ and propofol $(274.3 \pm 222.8 \mathrm{mg})$; mean examination time was $32.9 \pm 21.2 \mathrm{~min}$. A new PTCD was performed in eight cases and a PTCD dilation and a PTCD exchange in six and six cases, respectively.

Study outcomes

Study outcomes are summarized in Table 2.

Primary study outcome

The mean cumulative duration of apnea according to capnography was significantly longer than the mean cumulative duration of clinically detected apnea $(207.5 \pm 348.8$ s versus $8.2 \pm 17.9 \mathrm{~s} ; \mathrm{P}=0.015)$.

Secondary study outcomes

Capnographic monitoring revealed 113 episodes of apnea in 16 of $20(80 \%)$ patients. Clinical observation revealed seven episodes of apnea in six of 20 patients ( $30 \% ; \mathrm{P}=0.001$ for difference in patients). All clinically observed episodes were also apparent on capnography.

Vital parameters: Fifteen events of oxygen desaturation and three events of hypoxemia occurred in 10 of 20 patients (50\%) and three of $20(15 \%)$ patients, respectively. No patient experienced bradycardia. Two of 20 patients (10\%) developed transient hypotension. Three of $20(15 \%)$ patients required increased oxygen supplementation (>2 L/min) after the occurrence of hypoxemia.

Relationship among ventilation, oxygen desaturation and hypoxemia: Oxygen desaturation was predicted in eight of 15 cases by capnography, with a mean of $37.5 \pm 35.9 \mathrm{~s}$ in advance (range $15 \mathrm{~s}$ to $120 \mathrm{~s}$ ) and in two of 15 cases by clinical observation. Hypoxemia was predicted in three of three cases by capnography (29 s, $35 \mathrm{~s}$ and $52 \mathrm{~s}$ in advance, mean $38.7 \pm 11.9 \mathrm{~s}$ ) and in one-third of cases by clinical observation. Seven of 15 events of oxygen desaturation $(46.7 \%)$ and zero of three events $(0 \%)$ of hypoxemia occurred without capnographic detection of apnea as defined above (exhaled $\mathrm{PCO}_{2}<8 \mathrm{mmHg}$ for $\geq 15 \mathrm{~s}$ ). 
Capnography did not demonstrate any false-positive episodes of apnea or altered ventilation that could be judged by clinical observation, and hypoxemia as indicated by pulse oxymetry.

Quality of sedation: Patient cooperation, as rated by the examiner after the procedure, was $8.5 \pm 1.3$ on a numerical analogue scale from 1 to 10 . Patients' satisfaction revealed a mean value of $9.1 \pm 1$.6.

Recovery: The time from the end of endoscopy until the patient opened his/her eyes and until leaving the procedure room was $4.8 \pm 3.3 \mathrm{~min}$ and $10.1 \pm 5.4 \mathrm{~min}$, respectively.

Serious adverse events: No patient required assisted ventilation. There were no serious adverse events, such as respiratory failure, orotracheal intubation, permanent disability or death, due to sedation.

\section{DISCUSSION}

PTCD, which is usually performed by gastroenterologists or interventional radiologists in specialized centres, requires procedural sedation in most patients. To avoid sedation-related side effects, such as hemodynamic instability, airway obstruction, aspiration or respiratory depression, the use of automatic monitoring, including blood pressure measurements and pulse oximetry as well as clinical observation for the detection of apnea, is mandatory $(2-4,9,10)$. However, there is evidence that most episodes of respiratory depression remain undetected by visual assessment and pulse oximetry, but can be detected by the use of capnography in nonintubated patients. This was first reported by Vargo et al (11) in a study involving 49 patients who received midazolam and meperidine sedation during therapeutic upper endoscopy. There is also evidence that capnography can reduce oxygen desaturation and hypoxemia during routine endoscopic procedures such as colonoscopy $(12,13)$. The advantage of capnography has also been shown for procedural sedation during invasive procedures in the emergency department (14). A recent meta-analysis including 332 patients from five studies reported that the addition of capnography in patient monitoring enhanced the surveillance of respiratory events during procedural sedation (5).

For the first time, the present study evaluated the use of capnography for procedural sedation during PTCD. We found that capnographic monitoring revealed episodes of apnea to a greater extent (as shown by a longer mean cumulative duration and a greater number of detected apnea episodes) than clinical observation and standard monitoring.

We defined apnea as a decrease of expired $\mathrm{CO}_{2}<8 \mathrm{mmHg}$ for $\geq 15 \mathrm{~s}$ according to previous published studies $(7,8)$. Different definitions of apnea, such as cessation of respiratory activity $>30 \mathrm{~s}$, have been previously reported $(11,13)$. In our study, the overall number of capnographically detected episodes of apnea, as well as the percentage of patients in which apnea was capnographically detected, were higher compared with other studies using capnography for procedural sedation $(5,11,13,14)$. On one hand, this may be explained by the variation in apnea definitions. On the other hand, the different types of investigated interventions require different levels of sedation. Moreover, the choice of sedative drugs and baseline characteristics of patients differed across studies. In our study, the majority of patients were classified ASA 3; hence, these patients had comorbities and may have been prone to developing apnea when receiving procedural sedation for PTCD, which is a rather invasive procedure.

In previously published studies investigating sedation in patients undergoing PTCD, a combination of the opioid fentanyl and the short-acting benzodiazepine midazolam was used most often to achieve effective sedation and analgesia (15-17). Currently, the short-acting hypnotic agent propofol is increasingly used for procedural sedation (eg, for complex gastrointestinal procedures) due to its superior pharmacokinetic properties $(18,19)$ and is listed in current guidelines $(2,4,20)$. In our study, we used propofol sedation in combination with midazolam for PTCD and achieved good-quality sedation as rated by examiner and patient satisfaction, as well as a fast recovery time of approximately $10 \mathrm{~min}$. However, because of the high number of apnea events that were detected by capnography, we have to assume that in many cases, the patients passed through the level of deep sedation.

In our study, the majority of capnographically detected apnea did not lead to oxygen desaturation measured by pulse oximetry. Similar observations were previously reported by our working group in a recent study (12). This can be explained by the fact that not all episodes of disturbed ventilation result in hypoxemia, particularly in the presence of supplemental oxygen, which elevates the baseline partial pressure of oxygen in these patients. However, pulse oximetry is an exclusive measure of hemoglobin oxygenation that reflects oxygen supply but does not adequately reflect the ventilatory status of the patient (21).

Furthermore, approximately one-half of the events of oxygen desaturation occurred in the absence of apnea as defined in our study. These events could have been due to subclinical hypoventilation but could also have been related to other factors such as aspiration, coughing or hemodynamic instability. The other one-half of oxygen desaturations, including all episodes of hypoxemia, were related to capnographically detected apnea, which occurred a mean of $38.7 \mathrm{~s}$ in advance of hypoxemia. Only one episode of hypoxemia was detected clinically. Hence, capnography is able to predict respiratory complications better than clinical surveillance and allows early countermeasures before the occurrence of hypoxemia. However, it must be noted that the presence of a normal capnogram does not guarantee sufficient oxygenation.

Based on the findings of our study, revealing a high prevalence of undetected episodes of apnea by standard monitoring during procedural sedation for PTCD, it is reasonable to assume that the additional use of capnographic surveillance could help to improve patient safety during this procedure. This is highlighted by prospective randomized outcome studies that have shown that capnographic monitoring of respiratory activity reduces the incidence of oxygen desaturation and hypoxemia during endoscopic procedural sedation in children under benzodiazepine/opioid sedation (7) as well as in adults who underwent endoscopic retrograde cholangiography or endoscopic ultrasound with benzodiazepine/opioid sedation (8). Thus, the recently published multisociety sedation curriculum for gastrointestinal endoscopy concluded that capnography may be beneficial in the pediatric population and in adults undergoing prolonged therapeutic procedures (22). PTCD is also an advanced procedure and is applied to patients with high comorbidity and an increased risk of cardiopulmonary complications.

Our study was subject to some general limitations. The sample size was small and the study was performed in a single academic centre. It was not designed to be an outcome study with an interventional group and a control group. Instead, we only performed an interindividual analysis of the data comparing the cumulative duration of detected apnea. A further limitation exists regarding the exact capnographic measurement of the end-expiratory $\mathrm{CO}_{2}$ value in the mixed exhalation air in the oral/nasal cavity, which is essential for capnometry. However, capnography relies on the wave form rather than on absolute endexpiratory values and trends can be evaluated in the absence of exact absolute values.

\section{CONCLUSION}

Capnographic monitoring is superior to clinical surveillance in the detection of apnea and in the prediction of oxygen desaturation during procedural sedation for PTCD. Further randomized outcome studies are needed to validate whether the use of capnography is also able to improve patient safety in the setting of procedural sedation for PTCD.

DISCLOSURES: Material support of the study has been provided by Covidien (USA). The company did not have any input on the study design, interpretation of the results or in drafting the manuscript. 


\section{REFERENCES}

1. Charton JP, Shim CS, Neuhaus H. Percutaneous transhepatic cholangiography and cholangioscopy. In: Classen M, Tytgat GNJ, Lightdale CJ, eds. Gastroenterological Endoscopy, 2nd edn. Stuttgart: Thieme; 2010:136-49.

2. Dumonceau JM, Riphaus A, Aparicio JR, et al. European Society of Gastrointestinal Endoscopy, European Society of Gastroenterology and Endoscopy Nurses and Associates, and the European Society of Anaesthesiology Guideline: Non-anesthesiologist administration of propofol for GI endoscopy. Endoscopy 2010;42:960-74.

3. Lichtenstein DR, Jagannath S, Baron TH, et al. Standards of Practice Committee of the American Society for Gastrointestinal Endoscopy, Sedation and anesthesia in GI endoscopy. Gastrointest Endosc 2008;68:815-26.

4. Riphaus A, Rabofski M, Wehrmann T. Endoscopic sedation and monitoring practice in Germany: Results from the first nationwide survey. Z Gastroenterol 2010;48:392-7.

5. Waugh JB, Epps CA, Khodneva YA. Capnography enhances surveillance of respiratory events during procedural sedation: A meta-analysis. J Clin Anesth 2011;23:189-96.

6. Schmitz BD, Shapiro BA. Capnography. Respir Care Clin N Am 1995; 1:107-17.

7. Lightdale JR, Goldmann DA, Feldman HA, Newburg AR, DiNardo JA, Fox VL. Microstream capnography improves patient monitoring during moderate sedation: A randomized, controlled trial. Pediatrics 2006;117:1170-8.

8. Qadeer MA, Vargo JJ, Dumot JA, et al. Capnographic monitoring of respiratory activity improves safety of sedation for endoscopic cholangiopancreatography and ultrasonography. Gastroenterology 2009;136:1568-76.

9. Knape JT, Adriaensen H, van Aken H, et al. Guidelines for sedation and/or analgesia by non-anaesthesiology doctors. Eur J Anaesthesiol 2007;24:563-7.

10. American Society of Anesthesiologists Task Force on Sedation and Analgesia by Non-Anesthesiologists. Practice guidelines for sedation and analgesia by non-anesthesiologists. Anesthesiology 2002;96:1004-17.

11. Vargo JJ, Zuccaro G Jr, Dumot JA, Conwell DL, Morrow JB, Shay SS. Automated graphic assessment of respiratory activity is superior to pulse oximetry and visual assessment for the detection of early respiratory depression during therapeutic upper endoscopy. Gastrointest Endosc 2002;55:826-31.
12. Beitz A, Riphaus A, Meining A, et al. Capnographic monitoring reduces the incidence of arterial oxygen desaturation and hypoxemia during propofol sedation for colonoscopy: A randomized, controlled study (ColoCap Study). Am J Gastroenterol 2012;107:1205-12.

13. Cacho G, Pérez-Calle JL, Barbado A, Lledó JL, Ojea R, Fernández-Rodríguez CM. Capnography is superior to pulse oximetry for the detection of respiratory depression during colonoscopy. Rev Esp Enferm Dig 2010;102:86-9.

14. Deitch K, Miner J, Chudnofsky CR, Dominici P, Latta D. Does end tidal $\mathrm{CO}_{2}$ monitoring during emergency department procedural sedation and analgesia with propofol decrease the incidence of hypoxic events? A randomized, controlled trial. Ann Emerg Med 2010;55:258-64.

15. Hatzidakis AA, Charonitakis E, Athanasiou A, et al. Sedations and analgesia in patients undergoing percutaneous transhepatic biliary drainage. Clin Radiol 2003;58:121-7.

16. Kim TH. Safety and effectiveness of moderate sedation for radiologic non-vascular intervention. Korean J Radiol 2006;7:125-30.

17. Skehan SJ, Malone DE, Buckley N, et al. Sedation and analgesia in adult patients: Evaluation of a staged-dose system based on body weight for use in abdominal interventional radiology. Radiology 2000;216:653-9.

18. Riphaus A, Stergiou N, Wehrmann T. Sedation with propofol for routine ERCP in high-risk octogenarians: A randomized, controlled study. Am J Gastroenterol 2005;100:1957-63.

19. Vargo JJ, Zuccaro G Jr, Dumot JA, et al. Gastroenterologistadministered propofol versus meperidine and midazolam for advanced upper endoscopy: A prospective, randomized trial. Gastroenterology 2002;123:8-16.

20. Vargo JJ, Cohen LB, Rex DK, et al; American Association for the Study of Liver Diseases; American College of Gasteroenterology. Nonanesthesiologist administration of propofol for GI endoscopy. Gastroenterology 2009;137:2161-7.

21. Rubin DM, Eisig S, Freeman K, Kraut RA. Effect of supplemental gases on end-tidal $\mathrm{CO}_{2}$ and oxygen saturation in patients undergoing fentanyl and midazolam outpatient sedation. Anesth Prog 1997;44:1-4.

22. Vargo JJ, Delegge MH, Feld AD, et al. Multisociety Sedation Curriculum for Gastrointestinal Endoscopy. Am J Gastroenterol 2012 May 22 (Epub ahead of print) doi: 10.1038/ajg.2012.112. 


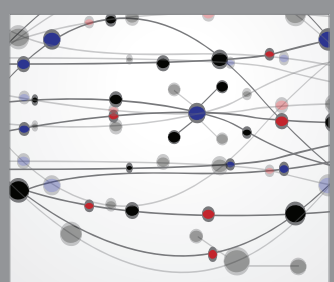

The Scientific World Journal
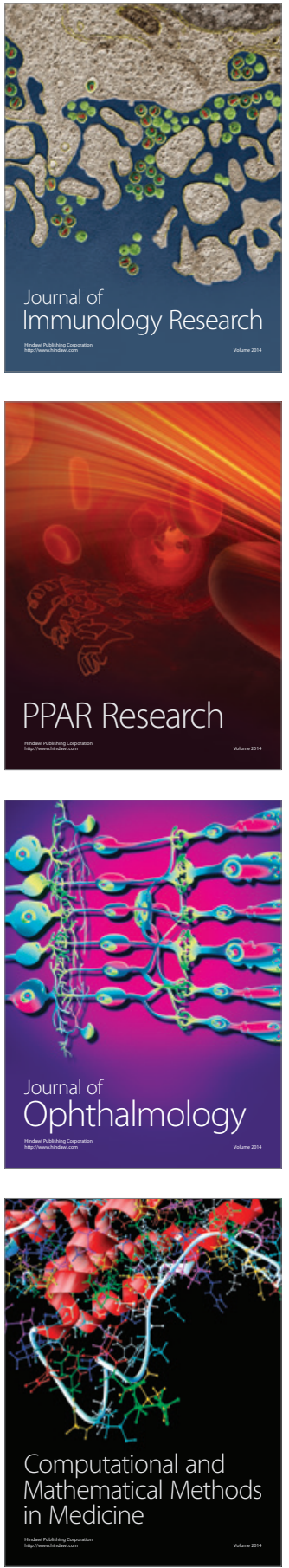

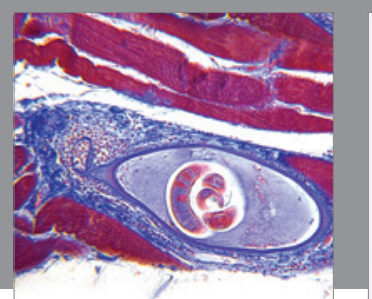

Gastroenterology Research and Practice

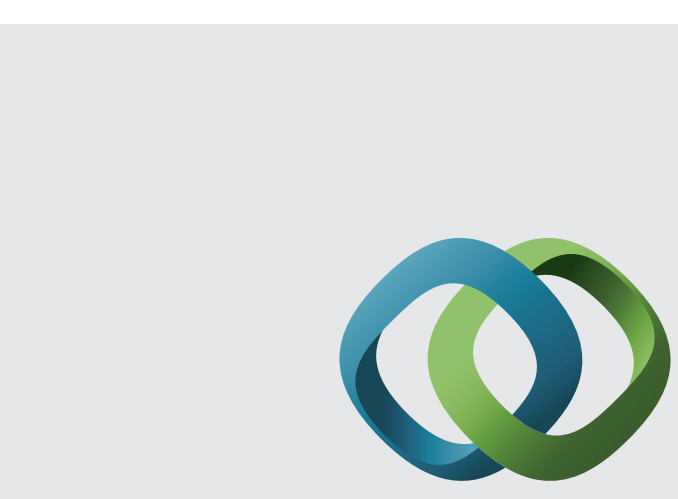

\section{Hindawi}

Submit your manuscripts at

http://www.hindawi.com
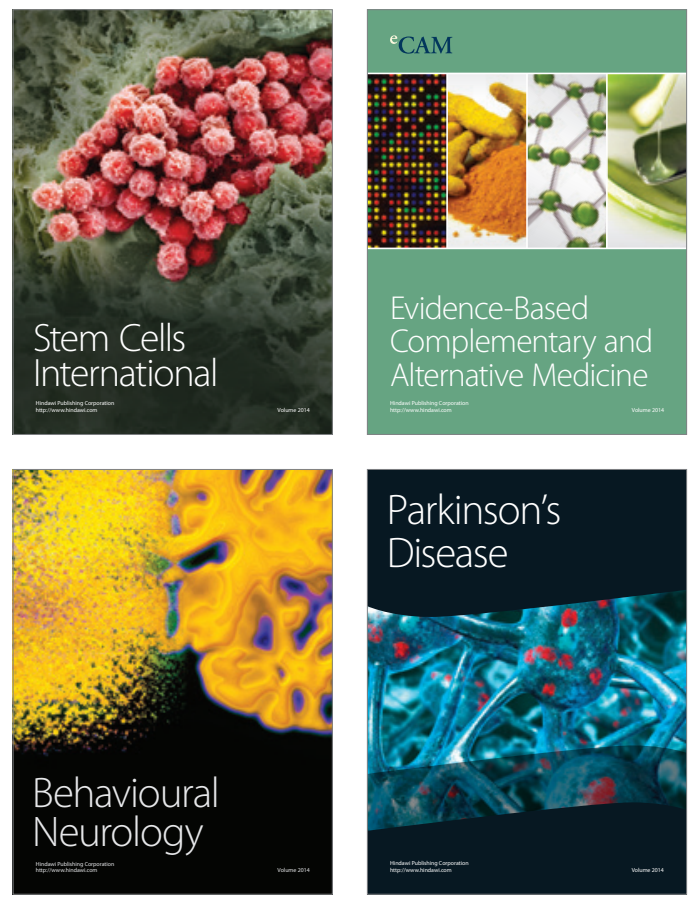
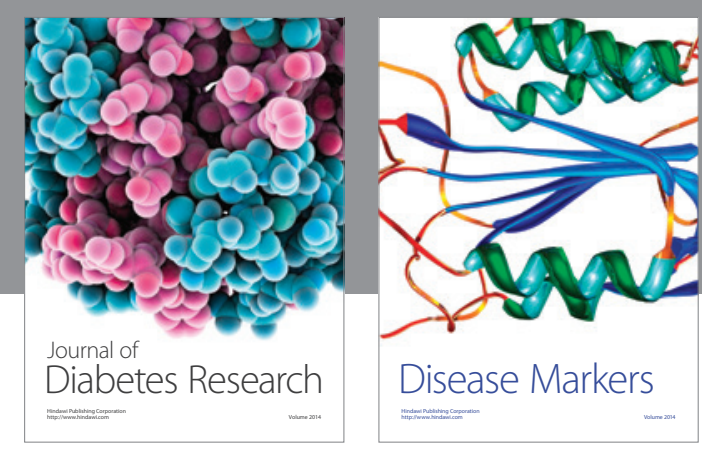

Disease Markers
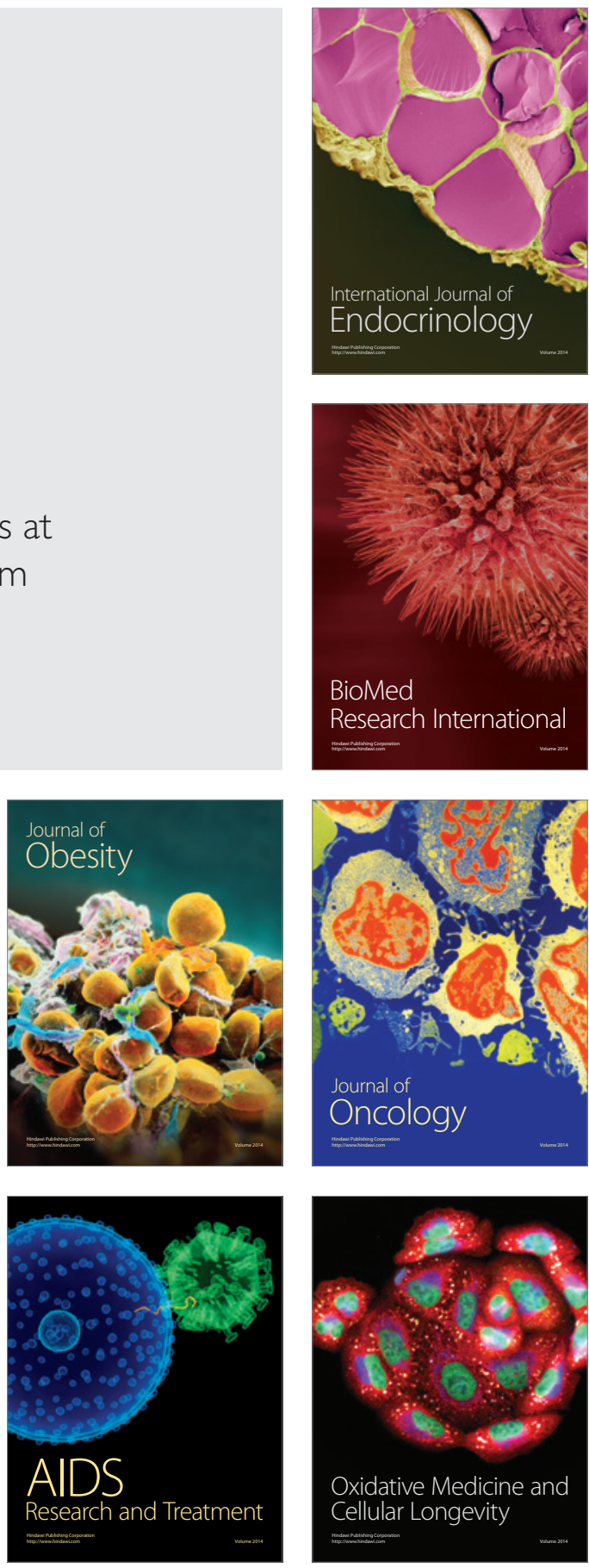